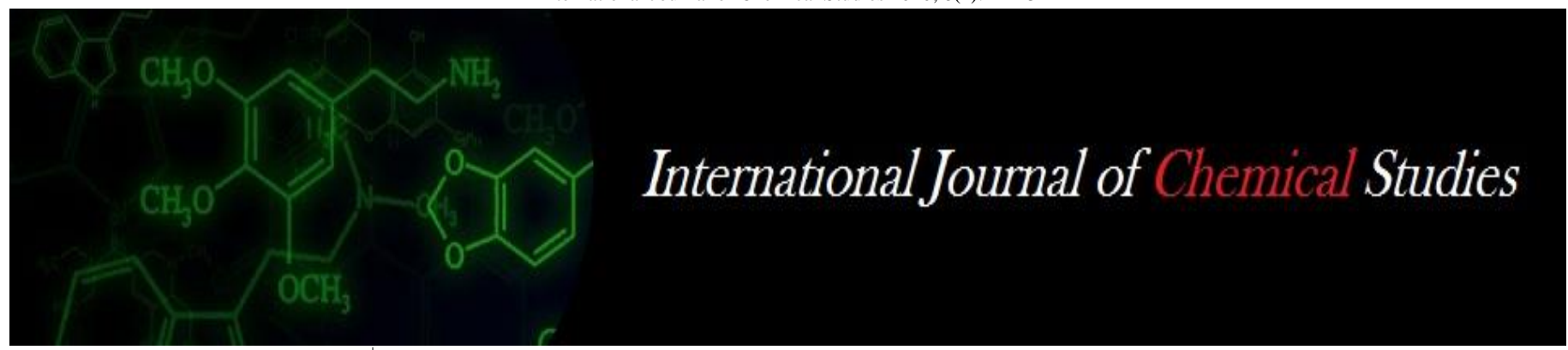

P-ISSN: 2349-8528

E-ISSN: 2321-4902

IJCS 2020; 8(1): 41-43

(C) 2020 IJCS

Received: 21-11-2019

Accepted: 25-12-2019

Ankit Rawat

Department of Food Technology, Sardar Vallabhbhai Patel

University of Agriculture \& Technology, Meerut, Uttar Pradesh, India

\section{Mukul Tyagi}

Department of Electrical

Engineering, Neelkanth inst. of

Engg. \& Technology, Meerut,

Uttar Pradesh, India
Corresponding Author:

Ankit Rawat

Department of Food Technology,

Sardar Vallabhbhai Patel

University of Agriculture \&

Technology, Meerut, Uttar

Pradesh, India

\section{Plant microbial fuel cell based green power generation along with soil and wastewater treatment: A mini review}

\author{
Ankit Rawat and Mukul Tyagi
}

DOI: https://doi.org/10.22271/chemi.2020.v8.i1a.8342

\begin{abstract}
Wetlands along with plant microbial fuel cell (PMFC) can be utilized for large power generation. Emission of greenhouse gases is lesser relative to conventional MFC technique and direct chemical to electrical conversion ensure high efficiency with treatment of polluted soil. If soil polluted with metal is filled with soil and plantation in cathode chamber of PMFCs then root zone oxygen leakage could be used for aeration requirement. Hence a parallel solution towards electricity generation, wastewater and soil matrix decontamination is obtained. This paper gives theoretical brief possibility of PMFCs effectiveness for electricity generation and soil treatments.
\end{abstract}

Keywords: Wastewater, plant microbial fuel cell (PMFC), microbial fuel cell (MFC), power generation

\section{Introduction}

Microbial fuel cell (MFC) is a device in which microbial action on wastewater results in electricity. it comprises two chambers separated by proton exchange membrane (PEM) containing two electrodes namely as positive and negative electrode similar to a ordinary cell and is termed as MFC ${ }^{[1,8]}$. Proton and electron are obtained at positive electrode when microbes consume substrate as carbon source anaerobically. EMF between electrodes in MFC causes electron flow from anode to cathode through external circuit, while proton flow takes place internally through proton exchange membrane inside the MFC from anode to cathode ${ }^{[1,}$ 3, 6]. Electron reaches cathode through external circuit and reacts with proton reaching the chamber through the PEM [9] internally, giving raise to oxygen reduction into water. In presence of the active microbes oxidation of the substrate takes place on anode which results in carbon dioxide formation, which may be in any form of hydrocarbon as there is a wide variety of wastewater ${ }^{[1,2]}$.

A theoretical solution has been proposed in this paper using some alternate material in PEM ${ }^{[7]}$ and usage of plants in cathode chamber and cathode chamber development with bio char [2] after a detailed study of Cathode breathing, Generation of electron and proton is a biological process, PMFC utilizes natural self-healing property ${ }^{[9]}$ for electrochemical reactions i.e. systematically reduction of $\mathrm{O}_{2}$ and oxygen supplies at cathode breathing through plants.

Prior knowledge about the oxygen leakage in the root zone of wetlands leads to Idea of usage of plantation at cathode. This oxygen leakage through lateral roots of from the plants will satisfy the need of aeration at cathode with simultaneous deposition of $\mathrm{CO}_{2}$ through plants leading towards the theoretical solution of at least two problems associated with existing microbial fuel cells (MFCs) with one more advantage of relatively power generation at larger scale ${ }^{[1,3]}$.

If cathode chamber is being planted using contaminated soil, plant capacity for making metal bioavailable could be harnessed in complex soil matrix treatment also. The reaction which through which metals will be either up taken or it will be deposited on the roots of the plants in anyone of the forms of metal compounds as oxide, hydroxide, carbonate, bicarbonate, sulphates and sulphides ${ }^{[9]}$. Not all the metals have been studied this way but this paper is just an approach to seek connection with redox reactions occurring in natural systems establishment along with power generation ${ }^{[1,9]}$.

These contaminants are very complex structured to be consumed by microbial action and if 
these contaminations reach water source it will be problem for aquatic life and with aquatic life and if that water is being consumed by humans it will create health issues as well ${ }^{[9]}$.

Usage of rice ${ }^{[7]}$, phragmites and canna ${ }^{[4,5]}$ have showed the capability of better removal efficiency of heavy metals ${ }^{[9]}$ and several hydrocarbons ${ }^{[9]}$, nutrients ${ }^{[8]}$ through plants as a greener and sustainable development in power generation making it as an alternative source of electricity extraction to meet daily increasing power demand. As usage of plantation is globally accepted for wastewater and contaminated soil treatment it emits $\mathrm{CH} 4$ while hydrocarbons uptake ${ }^{[8]}$.

This paper is showing only the possibility of present complex issues of treatment and disposal of wastes leading towards the greener production of power directly from organic substrate. It has been observed that PMFCs in connection with wetlands have shown the greater electricity generation capacity as a cheaper solution. It makes a very viable solution for implementation for developed nations. But still there are many problems associated with large scale applications as this connection is still under study and it has many stages to be cleared starting with making cheaper as this is very costly technology [2] for full scale application [9]. As power generation through this combination has been reported as 450$550 \mathrm{~mW} / \mathrm{m}^{2}{ }^{[2]}, 1600-3200 \mathrm{~W} / \mathrm{m}^{2}{ }^{[7]}$ and $240 \mathrm{~mW} / \mathrm{m}^{2}{ }^{[8]}$.

\section{PMFC usage possibilities}

Any technological remedy implementation depends upon the factor that how much that technology is serviceable, sustainable and susceptible. In the present scenario wastewater treatment has been proposed through various techniques but usage of PMFCs has advantages over MFCs are as follows:

- It can provide onsite electricity generation [9]

- It not only cuts down the greenhouse gasses emissions but also consumes $\mathrm{CO}_{2}$ through plantations.

- Its electricity generation is having life only for two years

- Running of PMFCs power capacity dips with the usage and with the environmental issues such as temperature, $\mathrm{pH}$ and deposition ${ }^{[2]}$

- $\quad$ PMFCs are very costly ${ }^{[8,9]}$

Phytoremediation is a very viable option for onsite treatment because of reasons as microbes growth got enhanced through attached growth as microbes got opportunity to form colonies on the roots, stem and on soil matrix. Vital role is being played in PMFCs by microbes and PEM as well for sake of treatment and electron generation as well ${ }^{[1,5,7]}$.

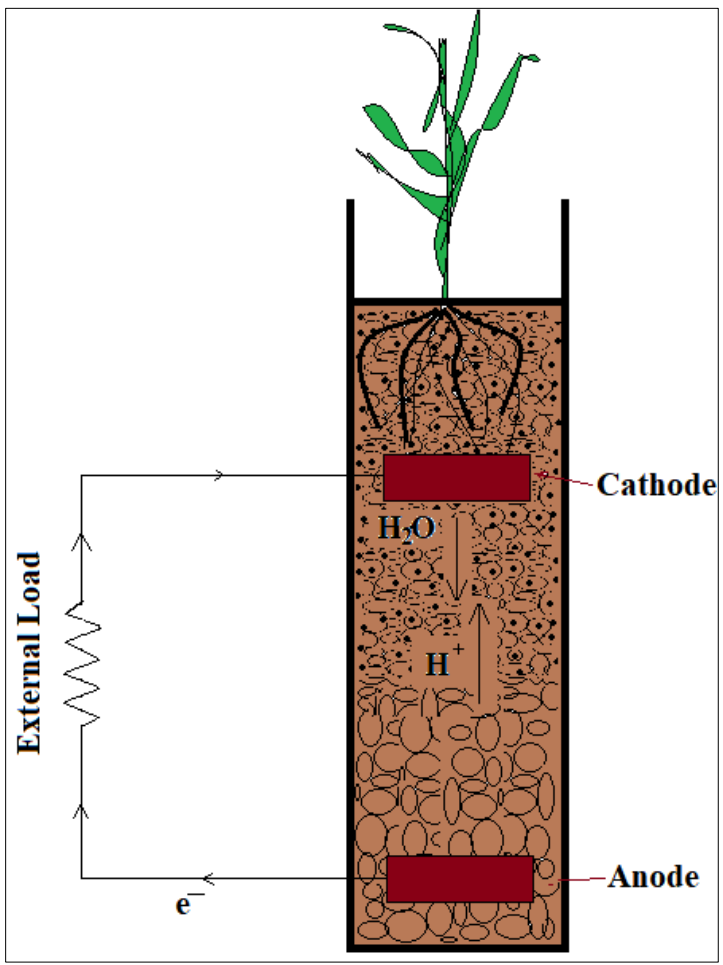

Fig 1: Schematic diagram of a typical PMFC

\section{Power generation capacity affecting factors}

More emphasis is laid in this paper that how various parameters variations are taking place, working in harmony leading towards the greener production in the present scenario of power generation and how workability should be increased in real time problem.

In PMFCs power generation is not only evaluated in accordance to the current flown in the circuit but also according to the power capacity ${ }^{[2,4]}$ or power density ${ }^{[8]}$ of that unit. Power capacity is expressed as in terms of power dissipated through external resistance in the form of ratios as EMF generated per unit area, per unit mass and per unit volume of the unit ${ }^{[8]}$.
Power density gives a rough idea about evaluation and understanding of the power generation taking place with several factors affecting power capacity.

These parameters are biological, chemical and physical which affect the generation of electron at anode and its flow into the external resistance. These parameters could be classified into various categories in accordance the characteristics. These parameters are as follows:

- Biological: Biomass concentration and biofilm formation on anode

- Chemical: Chemical composition of substrate, concentration of substrate

- Physical: $\mathrm{pH}$, temperature of the effluent ${ }^{[7,9]}$ 
- Other than major classification of parameters above a few more parameters affect the efficacy and efficiency of PMFCs, and are regarding running factors of the PFMCs are as follows:

- Plantation per $\mathrm{m}^{2}$ according to US-EPA standards for phytoremediation

- Weather variation

- $\quad$ Shape and size of the cell

- Hydraulics of the cell

- $\quad$ Surface overflow rate of the cell ${ }^{[7,8]}$

Regarding all these factors the complex behavior is being followed and researchers have suggested some improvements for better wastewater treatment with improved electrical efficiency with emissions as well. Some provisions on cathode chamber and on anode chamber are suggested and optimistic results have been found and reported as well [4, 6,7, ${ }^{8]}$. Results of the studies carried out suggest that with technical aspects the possibility of applications but still being expensive it still supports decentralized facility rather than centralized facility.

\section{Possibilities of affecting factors corrections}

Through studies and experiments done over the passage of time showed that there are many possibilities of making something more valuable and viable in dealing with pollution especially wastewater using MFC. MFCs showed this electricity production possibility along with $\mathrm{CO}_{2}$ emission at anode and constant need of $\mathrm{O}_{2}$ at cathode.

$\mathrm{CO}_{2}$ consumption for $\mathrm{O}_{2}$ generation is shown by plants with phytoremediation as well, which lead through PMFCs development. Reactions which take place on anode and cathode in MFCs and PMFCs are as follows:

\section{At Anode}

$\left(\mathrm{CH}_{2} \mathrm{OH}\right) n+\mathrm{H}_{2} \mathrm{O} \rightarrow \mathrm{CO}_{2}+\mathrm{H}++e^{-[8]}$

Mreduced $\rightarrow$ Moxidation $+e^{-[8]}$

Metals are represented as $\mathrm{M}$ in the above equation if present in the complex soil matrix.

\section{At cathode}

$\mathrm{O}_{2}+\mathrm{H++e}-\rightarrow \mathrm{H}_{2} \mathrm{O}^{[7,8]}$

Improvements made successfully and results are found to be quite promising but at laboratory scale. If cathode chamber is filled with soil matrix and plantation it would do treatment through soil matrix as filter, through plant uptake, through microbes present on the root zone and through microbes present at anode chamber as well simultaneously with power generation variations found to be 38 to $2760 \mathrm{kWh} / \mathrm{m}^{3}$ [9].

Some improvements considerations such as correction at anode only ${ }^{[2,6]}$, at cathode only ${ }^{[7]}$, at anode and cathode both as either keeping the material same but either in usage as solid or powdered or some other aspect as making it very handy and viable ${ }^{[8]}$. Some didn't do the same but they have opened a new possibility of bringing a new possibility of shape through the novelty in design as well ${ }^{[8]}$.

Improvements of soil ${ }^{[4,5]}$, application at cathode also been suggested as mixed with manure showed the appreciable increase in electricity generation, opening and verifying the existence of bioelectricity.

\section{Conclusion}

In this paper we suggest PMFC usage because with the rising problem of water pollution, soil pollution and meeting rising demands of energy and potable water is necessary because this technology has positive environmental impact with lesser amount of solids production with good removal efficiency. This technology is a bit complex but still it will be promising if by further studies on this technology it could be made economical.

\section{References}

1. Chen Z, Zhu BK, Jia WF, Liang JH, Sun GX. Can electrokinetic removal of metals from contaminated paddy soils be powered by microbial fuel cells? Environmental Technology \& Innovation. 2015; 3:63-67.

2. Khudzari JM, Gariépy Y, Kurian J, Tartakovsky B, Raghavan GV. Effects of biochar anodes in rice plant microbial fuel cells on the production of bioelectricity, biomass, and methane. Biochemical Engineering Journal. 2019; 141:190-199.

3. Li X, Wang X, Weng L, Zhou Q, Li Y. Microbial Fuel Cells for Organic-Contaminated Soil Remedial Applications: A Review. Energy Technology. 2017; 5(8):1156-1164.

4. Moqsud MA, Yoshitake J, Bushra QS, Hyodo M, Omine $\mathrm{K}$, Strik D. Compost in plant microbial fuel cell for bioelectricity generation. Waste management. 2015; 36:63-69.

5. Sarma PJ, Mohanty K. Epipremnumaureum and Dracaena braunii as indoor plants for enhanced bioelectricity generation in a plant microbial fuel cell with electrochemically modified carbon fiber brush anode. Journal of bioscience and bioengineering. 2018; 126(3):404-410.

6. Timmers RA, Strik DP, Hamelers HV, Buisman CJ. Electricity generation by a novel design tubular plant microbial fuel cell. Biomass and Bioenergy. 2013; 51:6067.

7. Wetser K, Sudirjo E, Buisman CJ, Strik DP. Electricity generation by a plant microbial fuel cell with an integrated oxygen reducing biocathode. Applied energy. 2015; 137:151-157.

8. Wetser K, Liu J, Buisman C, Strik D. Plant microbial fuel cell applied in wetlands: spatial, temporal and potential electricity generation of Spartinaanglica salt marshes and Phragmitesaustralis peat soils. Biomass and Bioenergy. 2015; 83:543-550.

9. Yadav AK, Dash P, Mohanty A, Abbassi R, Mishra BK. Performance assessment of innovative constructed wetland-microbial fuel cell for electricity production and dye removal. Ecological Engineering. 2012; 47:126-131. 